\title{
Synthesis of Gold Nanoparticles with Anisotropy of the Optical Properties
}

\author{
Tatyana V. Trofimova*, Svetlana V. Saykova, \\ Diana I. Saykova and Dmitriy I. Chistyakov \\ Siberian Federal University \\ 79 Svobodny, Krasnoyarsk, 660041 Russia
}

Received 22.09.2016, received in revised form 20.10.2016, accepted 04.12.2016

The work is devoted to the selection of optimal conditions for the synthesis of anisotropic gold nanoparticles, which can be used in solar energy, catalysis, chemical sensors and in medicine, where it is offered to carry out the diagnosis and therapy of cancer patients with their help. The mathematical model is obtained. It reflects the influence of reaction parameters in the synthesis of gold nanoparticles bipyramidal form. We found optimal conditions to form the bipyramid of gold with size about 76x24 $\pm 5 \mathrm{~nm}$ and long-wave maximum of the localized surface plasmon resonance (LSPR) at $870 \mathrm{~nm}$. Also we optimized a technique to obtain gold nanorods with different axial ratio and the position of the wavelength maximum of the LSPR in the range of $730 \div 850 \mathrm{~nm}$. The obtained nanorods have dimensions about $23 \pm 1 \times 7 \pm 0,2 \mathrm{~nm}, 20 \pm 2,5 \times 5 \pm 0,5 \mathrm{~nm}, 29 \pm 1,5 \times 6 \pm 0,1 \mathrm{~nm}$, confirmed by transmission electron microscopy.

Keywords: gold nanorods, gold bipyramid, hydrosols, synthesis.

DOI: $10.17516 / 1998-2836-2016-9-4-496-503$.

(c) Siberian Federal University. All rights reserved

* Corresponding author E-mail address: ttv91@mail.ru 


\title{
Синтез наночастиц золота, обладающих анизотропией оптических свойств
}

\author{
Т.В. Трофимова, С.В. Сайкова, \\ Д.И. Сайкова, Д.И. Чистяков \\ Сибирский федеральный университет \\ Россия, 660041, Красноярск, пр. Свободный, 79
}

Статья посвящена подбору оптимальных условий синтеза анизотропных наночастиц золота, которые могут быть использованы в солнечной энергетике, катализе, для создания химических сенсоров и в медицине, где с их помощью предлагается осуществлять терапию и диагностику онкологических больных. В ходе исследования получена математическая модель, отражающая влияние реакиионных параметров на синтез наночастии золота бипирамидальной формыл. В найденных нами оптимальных условиях формируются бипирамиды золота размером 76х24 \pm 5 нм с длинноволновым максимумом поверхностного плазмонного резонанса (ППР) при 870 нм. Также оптимизированы методики получения наностержней золота с различным осевым

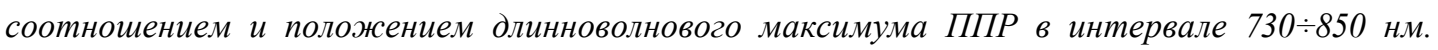

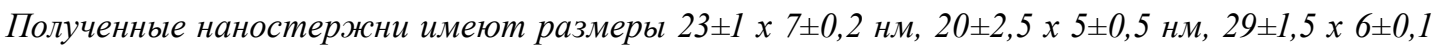
нм, что подтверждено данными просвечивающей электронной микроскопии.

Ключевые слова: наностержни золота, бипирамиды золота, гидрозоли, синтез.

\section{Введение}

С начала 2000-х гг. наночастицы (НЧ) золота, обладающие анизотропными оптическими свойствами, привлекают повышенное внимание ученых из-за их перестраиваемых плазмонных свойств, которые делают их идеальными кандидатами для широкого круга применения: в солнечной энергетике, фотовольтатике, для создания химических сенсоров и др. [1]. Первым успешным примером анизотропной плазмонной наноструктуры, синтезированной методом мокрой химии, были золотые наностержни (nanorods), кроме того, оптической анизотропией обладают нанопризмы, плоские частицы, бипирамиды [2].

Наибольший интерес представляет применение наночастиц золота с оптической анизотропией в медицине, где с их помощью предлагается осуществлять терапию онкологических больных. В течение последних нескольких лет разрабатываются новые методы регулируемого и локализованного нагрева раковых клеток. В частности, при освещении лазерным излучением наночастицы могут эффективно генерировать необходимое для гибели клеток тепло. Однако для этого необходимо, чтобы максимум ППР таких частиц находился в так называемом биологическом окне. Биологическое окно - спектральный диапазон, где ткани становятся частично прозрачными вследствие одновременного снижения поглощения и рассеяния. Первое окно расположено в интервале длин волн 700-980 нм, что соответствует спектральной области поглощения гемоглобина и воды. В этом спектральном диапазоне поглощение сильно падает, но

$$
-497-
$$


присутствует остаточное рассеяние. Второе биологическое окно находится в интервале длин волн 1000-1400 нм и соответствует полосам поглощения воды. В этом спектральном диапазоне поглощение не исчезает полностью, но оптическое рассеяние сводится к минимуму из-за больших длин волн [3].

Анизотропные НЧ золота вследствие своего несферического строения имеют два максимума поглощения: около 520 нм и в интервале 700-900 нм в зависимости от соотношения их геометрических параметров. Положение второго максимума ППР позволяет использовать такие наночастицы в борьбе с раковой опухолью. Таким образом, создание быстрых, легких и надежных методов синтеза анизотропных НЧ золота является очень актуальной задачей.

Несмотря на большое количество работ, посвященных синтезу золотых наностержней, существует проблема воспроизводимости предложенных методик синтеза. Кроме того, до сих пор не решена задача контроля над соотношением длины и ширины наностержней (осевое отношение) в процессе их получения. Однако именно эта величина, а также морфология наночастиц - основные факторы, которые определяют их каталитическую, оптическую, поверхностную активность и фототермические свойства.

Синтезу нанокристаллов золота бипирамидальной формы посвящено ограниченное количество работ $[2,4-8]$, однако золотые бипирамиды отличаются своей монодисперсностью и способны к значительно большему усилению локального поля вследствие их острых вершин, чем наностержни и другие анизотропные НЧ золота. Следовательно, они могут вызывать существенно большее усиление комбинационного рассеяния, что позволит регистрировать сверхмалые концентрации химических и биологических веществ.

Целью данной работы является изучение влияния различных факторов на синтез анизотропных наночастиц золота, а также поиск оптимальных условий их синтеза.

\section{Экспериментальная часть}

Все используемые реактивы имели квалификацию «чда» и дальнейшей очистке не подвергались.

Синтез наночастиц золота бипирамидальной формы осуществляли по двухстадийной методике, предложенной в [2]. Первая стадия: к 4,7 мл раствора бромида цетилтриметиламмония (ЦТАБ) добавляли 0,025 мл $\mathrm{HAuCl}_{4}(\mathrm{C}=0,05 \mathrm{M})$, перемешивали на магнитной мешалке в течение нескольких минут и вводили при интенсивном перемешивании 0,3 мл $\mathrm{NaBH}_{4}$, оставляли при комнатной температуре в течение заданного времени. Раствор окрашивался в светло-коричневый цвет - раствор «зародышей». На второй стадии к 10 мл раствора ЦТАБ последовательно добавляли 0,19 мл $1 \mathrm{M} \mathrm{HCl}, 0,1$ мл $\mathrm{HAuCl}_{4}(\mathrm{C}=0,05 \mathrm{M})$, заданные объемы растворов $\mathrm{AgNO}_{3}(\mathrm{C}=0,01 \mathrm{M})$, аскорбиновой кислоты $(\mathrm{C}=0,1 \mathrm{M})$ и «зародышей». При введении аскорбиновой кислоты раствор обесцвечивался, после добавления зародышей наблюдалось развитие окраски (переход красный - фиолетовый), которая с течением времени становилась более интенсивной. Синтез осуществляли в течение 1,5 ч.

Синтез наностержней золота осуществляли по модифицированной методике [8]: к 5 мл $0,001 \mathrm{M} \mathrm{HAuCl}_{4}$ (при температуре $25^{\circ} \mathrm{C}$ ) добавляли заданные объемы растворов ЦТАБ $(0,1 \mathrm{M})$ и $\mathrm{AgNO}_{3}(0,004 \mathrm{M})$, после чего раствор тщательно перемешивали. Далее добавляли 0,07 мл аскорбиновой кислоты $(0,1 \mathrm{M})$ и продолжали перемешивать раствор до полного обесцвечивания, за- 
тем немедленно вводили 0,015 мл $0,01 \mathrm{M}$ свежеприготовленного $\mathrm{NaBH}_{4}$, охлажденного до $0{ }^{\circ} \mathrm{C}$, и оставляли раствор без перемешивания на 6 ч.

Для выделения наночастиц золота золи центрифугировали в течение 30 мин при 10000 об/мин, осадок редиспергировали в воде и еще раз центрифугировали при тех же условиях для дополнительной очистки частиц от ЦТАБ, затем вновь редиспергировали осадок в дистиллированной воде.

Образовавшиеся гидрозоли, содержащие НЧ золота, изучали спектрофотометрическим методом. Оптические спектры поглощения были записаны в диапазоне длин волн от 400 до 1000 нм на приборе «Спекол 1300» в сантимертовой стеклянной кювете.

Просвечивающая электронная микроскопия была выполнена на микроскопе НT7700 (Hitachi, Япония) при ускоряющем напряжении 100 кВ. Для микроскопии каплю гидрозоля, содержащего наночастицы золота, наносили на медную сеточку с углеродным напылением и высушивали при комнатной температуре. Для определения среднего размера частиц выполняли анализ 1000 частиц из ряда изображений ПЭМ.

\section{Обсуждение результатов}

Процесс синтеза нанобипирамид золота по двухстадийной методике можно описать следующими уравнениями:

- получение сферических зародышей:

$$
8 \mathrm{HAuCl}_{4}+3 \mathrm{NaBH}_{4}+9 \mathrm{H}_{2} \mathrm{O}=8 \mathrm{Au}^{0}+3 \mathrm{H}_{3} \mathrm{BO}_{3}+3 \mathrm{NaCl}+29 \mathrm{HCl}
$$

- рост бипирамид:

$$
\begin{aligned}
& \mathrm{HAuCl}_{4}+\mathrm{C}_{6} \mathrm{H}_{8} \mathrm{O}_{6}=\mathrm{HAuCl}_{2}+\mathrm{C}_{6} \mathrm{H}_{6} \mathrm{O}_{6}+2 \mathrm{HCl}, \\
& 3 \mathrm{HAuCl}_{2}=\mathrm{HAuCl}_{4}+2 \mathrm{Au}+2 \mathrm{HCl} .
\end{aligned}
$$

Поиск оптимальных условий синтеза нанобипирамид золота проводили с использованием метода математического планирования и обработки результатов дробного факторного эксперимента ДФЭ $2^{7-4}$ (1/16 реплики полного факторного эксперимента) [6]. В качестве целевой функции (Y) выбрали положение второго (длинноволнового) максимума ППР гидрозолей наночастиц золота $\left(\lambda_{2}\right)$, в качестве независимых переменных $\left(\mathrm{X}_{\mathrm{i}}\right)$ - факторы, представленные в

\begin{tabular}{|c|c|c|c|c|c|c|c|}
\hline & $\mathrm{X}_{1}$ & $\mathrm{X}_{2}$ & $\mathrm{X}_{3}$ & $\mathrm{X}_{4}$ & $\mathrm{X}_{5}$ & $\mathrm{X}_{6}$ & $X_{7}$ \\
\hline & $\mathrm{t},{ }^{\circ} \mathrm{C}$ & $\mathrm{C}_{\mathrm{NaBH} 4}, \mathrm{M}$ & время, мин & $\mathrm{V}_{\text {зародышей}}$ МЛ & $\mathrm{V}_{\text {аск.к-ты, }}$, мЛ & $\mathrm{C}_{\text {ЦТАБ, }}, \mathrm{M}$ & $\mathrm{V}_{\mathrm{AgNO} 3}$, мЛ \\
\hline $\begin{array}{l}\text { Верхний уровень } \\
\text { варьирования }\end{array}$ & 30 & 0,1 & 10 & 0,012 & 3 & 0,1 & 1,2 \\
\hline $\begin{array}{l}\text { Нижний уровень } \\
\text { варьирования }\end{array}$ & 50 & 0,01 & 40 & 0,024 & 1 & 0,15 & 2,4 \\
\hline$b_{i}$ & 13 & $\underline{120}$ & -151 & 10 & 7 & 167 & 11 \\
\hline
\end{tabular}

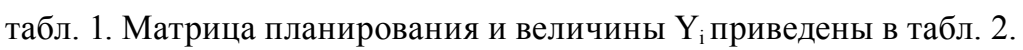

Таблица 1. Значения независимых переменных и коэффициентов полученного уравнения регрессии $\left(\mathrm{b}_{\mathrm{i}}\right)$

$$
-499-
$$


При реализации дробно-факторного эксперимента провели три серии опытов (оптический спектр лучшего опыта плана представлен на рис. 1, кривая 1), по результатам которых определили средние значения частных откликов $\left(\mathrm{Y}_{\mathrm{i}}\right)$, оценили ошибку воспроизводимости каждого опыта, рассчитали коэффициенты уравнения регрессии $\left(\mathrm{b}_{\mathrm{i}}\right)$, порог значимости коэффициентов регрессии $\left(\Delta \mathrm{b}=10,5, \mathrm{~b}_{0}=438\right)$ (табл. 1 , значимые коэффициенты подчеркнуты). Относительная ошибка эксперимента составляет $5 \%$.

В результате эксперимента получили уравнение регрессии, описывающее зависимость длины волны второго максимума ППР $\left(\lambda_{2}\right)$ от исследованных факторов:

$$
\lambda_{2}=438+13 \mathrm{x}_{1}+120 \mathrm{x}_{2}-151 \mathrm{x}_{3}+167 \mathrm{x}_{6}+11 \mathrm{x}_{7} \text {. }
$$

Наиболее значимы три фактора: концентрации ЦТАБ и $\mathrm{NaBH}_{4}$ и время синтеза зародышей. Меньшее влияние оказывают температура, объем нитрата серебра, незначимыми являются объемы аскорбиновой кислоты и зародышей. Адекватность полученной модели подтвердили на практике, сравнив экспериментальные результаты с рассчитанными по уравнению регрессии, используя критерии Фишера и Кохрена (табл. 2).

В дальнейших экспериментах (табл. 3) варьировали факторы в направлении, предсказанном моделью для поиска оптимума в новом факторном пространстве (крутое восхождение по Боксу-Уилсону). Полученные результаты представлены на рис. 1.

В найденных нами оптимальных условиях получены НЧ золота, в спектрах золей которых длинноволновый максимум ППР расположен при 870 нм (рис. 1, кривая 2), что соответствует первому биологическому окну.

Таблица 2. Матрица планирования ДФЭ $2^{3}$ и результаты практической проверки адекватности полученного уравнения регрессии

\begin{tabular}{|c|c|c|c|c|c|c|c|c|c|c|}
\hline $\begin{array}{c}\text { Номер } \\
\text { опыта }\end{array}$ & $\mathrm{X}_{0}$ & $\mathrm{X}_{1}$ & $\mathrm{X}_{2}$ & $\mathrm{X}_{3}$ & $\mathrm{X}_{4}$ & $\mathrm{X}_{5}$ & $\mathrm{X}_{6}$ & $\mathrm{X}_{7}$ & $\begin{array}{c}\mathrm{Y}_{\mathrm{i}} \\
\text { (эксп. значения) }\end{array}$ & $\begin{array}{c}\mathrm{Y}_{\mathrm{i}} \text { (расчетные } \\
\text { значения) }\end{array}$ \\
\hline 1 & + & - & - & - & + & + & + & - & 630 & 612 \\
\hline 2 & + & + & - & - & - & - & + & + & 643 & 660 \\
\hline 3 & + & - & + & - & - & + & - & + & 537 & 540 \\
\hline 4 & + & + & + & - & + & - & - & - & 547 & 544 \\
\hline 5 & + & - & - & + & + & - & - & + & 0 & -2 \\
\hline 6 & + & + & - & + & - & + & - & - & 0 & 2 \\
\hline 7 & + & - & + & + & - & - & + & - & 690 & 662 \\
\hline 8 & + & + & + & + & + & + & + & + & 615 & 598 \\
\hline
\end{tabular}

Таблица 3. Условия синтеза нанобипирамид золота

\begin{tabular}{|c|c|c|c|c|c|c|c|}
\hline \multirow{2}{*}{$\begin{array}{c}\text { Номер } \\
\text { опыта }\end{array}$} & $\mathrm{X}_{1}$ & $\mathrm{X}_{2}$ & $\mathrm{X}_{3}$ & $\mathrm{X}_{4}$ & $\mathrm{X}_{5}$ & $\mathrm{X}_{6}$ & $\mathrm{X}_{7}$ \\
\cline { 2 - 8 } & $\mathrm{t},{ }^{\circ} \mathrm{C}$ & $\mathrm{C}_{\text {NaвH4},}, \mathrm{M}$ & время, мин & $\begin{array}{c}\mathrm{V}_{\text {зародышей }}, \\
\text { мЛ }\end{array}$ & $\mathrm{V}_{\text {аск.к-ты, }}, \mathrm{MЛ}$ & $\mathrm{C}_{\text {цтАБ }}, \mathrm{M}$ & $\mathrm{V}_{\text {АgNO3 }}$, мЛ \\
\hline 1 & 30 & 0,1 & 25 & 0,024 & 0,1 & 0,1 & 1,2 \\
\hline 2 & 30 & 1,5 & 25 & 0,024 & 0,1 & 0,075 & 0,2 \\
\hline
\end{tabular}


На рис. 2 приведена микрофотография (просвечивающая электронная микроскопия) синтезированных частиц. Установлено, что формируются бипирамидальные НЧ золота с острыми вершинами размером $(76 \times 24 \pm 5)$ нм. Кроме того, на фотографии видны и близкие к сферическим нч размером 30-35 нм, выход бипирамид, согласно данным ПЭМ, составляет около 50 \%. В дальнейших исследованиях планируется подобрать условия синтеза, позволяющие увеличить выход бипирамид золота.

Для получения золотых наностержней использовали беззародышевый метод синтеза частиц. С целью получения НЧ с различным осевым соотношением оптимизировали условия путем варьирования объема растворов ЦТАБ $\left(5 \div 10\right.$ мл) и $\mathrm{AgNO}_{3}(0,25 \div 0,29$ мл). Результаты представлены на рис. 3.

С увеличением количества $\mathrm{AgNO}_{3}$ и ЦТАБ в растворе второй максимум ППР смещается в длинноволновую область, что соответствует увеличению осевого соотношения частиц. Кроме того, возрастает интенсивность пиков, что говорит об увеличении выхода наночастиц. Полученные образцы были исследованы методом просвечивающей электронной микроскопии (рис. 4). Установлено, что наностержни золота, синтезированные в этих опытах, имеют раз-

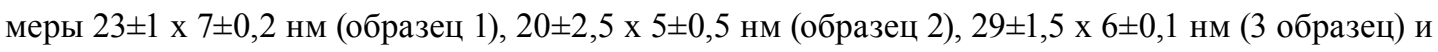
осевое соотношение $3,3,4$ и 4,8 соответственно.



Рис. 1. Оптические спектры гидрозолей НЧ золота: 1 - опыт 7 (табл. 2); 2 - опыт 2 (табл. 3), 3 - опыт 1 (табл. 3)

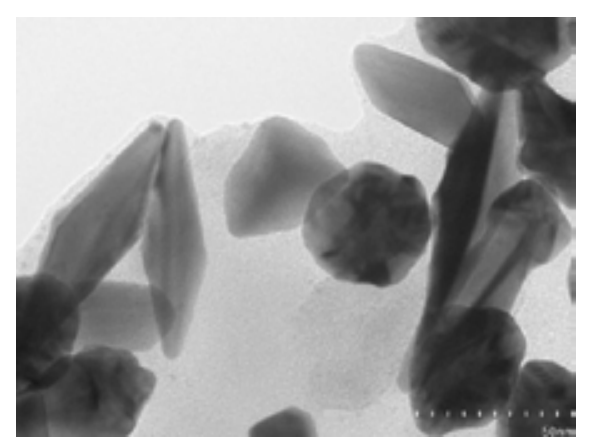

Рис. 2. Типичная микрофотография наночастиц золота, полученных в оптимальных условиях

$$
-501-
$$






a)



б)

Рис. 3: a - оптические спектры гидрозолей золота с различным содержанием $\mathrm{AgNO}_{3}: 0,25$ мл (1 образец), 0,27 мл (2 образец) и 0,29 мл (3 образец); б - внешний вид гидрозолей наностержней золота

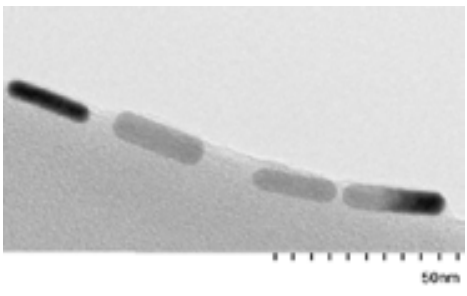

a)

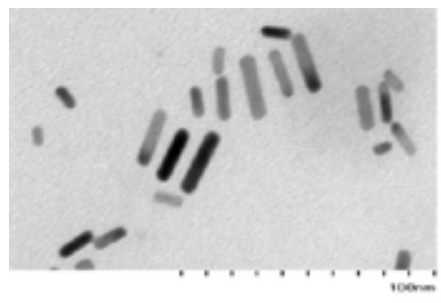

б)



B)

Рис. 4. Микрофотографии наностержней золота: а - образец 1 ; б - образец 2; в - образец 3

\section{Выводы}

Для синтеза наночастиц золота, обладающих анизотропией оптических свойств, было использовано два подхода (двухступенчатый метод зародышевого роста и одноступенчатый беззародышевый способ), приводящих к получению частиц различной морфологии (бипирамиды и наностержни).

Методом математического планирования и обработки результатов экспериментов ДФЭ $2^{7-4}$ изучено влияние различных факторов (температура, время, концентрация и объем реагентов) на синтез нанокристаллитов золота бипирамидальной формы. В соответствии с полученным уравнением регрессии, отражающим влияние указанных факторов, усовершенствована методика синтеза НЧ золота $\left(\mathrm{C}(\mathrm{CTAB})=0,075 \mathrm{M}, \mathrm{C}\left(\mathrm{NaBH}_{4}\right)=1,5 \mathrm{M}\right.$, время 25 мин, $\mathrm{V}\left(\mathrm{AgNO}_{3}\right)=0,2$ мл). По данным методов оптической спектроскопии и просвечивающей электронной микроскопии, полученные гидрозоли содержат наночастицы золота бипирамидальной формы $(76 \times 24 \pm 5$ нм) с положением второго максимума ППР при 870 нм.

C помощью одноступенчатого беззародышевого метода получены наностержни золота. Установлено, что с ростом концентрации $\mathrm{Ag}^{+}$в растворе увеличивается осевое соотношение частиц $(3 \div 4,8)$ и второй максимум ППР смещается в длинноволновую область $(730 \div 850$ нм). 
По данным просвечивающей электронной микроскопии, полученные частицы имеют размеры $23 \pm 1 \times 7 \pm 0,2$ нм, $20 \pm 2,5 \times 5 \pm 0,5$ нм, $29 \pm 1,5$ × $6 \pm 0,1$ нм.

В найденных нами оптимальных условиях получены НЧ золота, в спектрах золей которых длинноволновый максимум ППР расположен в диапазоне длин волн, соответствующих первому биологическому окну, что позволяет использовать данные частицы в медицине для терапии и диагностики онкологических больных.

Работа выполнена с использованием оборудования Центра коллективного пользования КНЦ СО РАН.

\section{Список литературы}

1. Scarabelli L., Sanchez-Iglesias A., Perez-Juste J., Liz-Marzan L. M. A «tips and tricks» practical guide to the synthesis of gold nanorods. J. Phys. Chem. Lett. 2015. Vol. 6, P. 4270-4279.

2. Lee J.-H., Gibson K. J., Chen G., Weizmann Y. Bipyramid-templated synthesis of monodisperse anisotropic gold nanocrystals. Nature Communications 2015. Vol. 6, P. 85-71.

3. Jaque D., Mart'inez Maestro L., Haro-Gonzalez P., Benayas A., Plaza J. L. Nanoparticles for photothermal therapies. Nanoscale 2014. Vol. 6, P. 94.

4. Liu M., Guyot-Sionnest P. Mechanism of Silver (I) - Assisted Growth of Gold Nanorods and Bipyramids. J. Phys. Chem. 2005. Vol. 109, P. 22192-22200.

5. Yoo H., Jang M. H., Size-controlled synthesis of gold bipyramids using an aqueous mixture of CTAC and salicylate anions as the soft template. Nanoscale 2013. Vol. 5, P. 6708-6712.

6. Navarro J. R. G., Synthesis of PEGylated gold nanostars and bipyramids for intracellular uptake. Nanotechnology 2012. Vol. 23, P. 465-602.

7. Personick M. L., Synthesis and isolation of $\{110\}$-faceted gold bipyramids and rhombic dodecahedra. Journal of the American Chemical Society. 2011. Vol. 133, P. 6170-6173.

8. Qi Y., Highly improved synthesis of gold nanobipyramids by tuning the concentration of hydrochloric acid. Journal of Nanoparticle Research 2016. Vol. 18, P. 1-16.

9. Ali M. Synthesis and optical properties of small Au nanorods using a seedless growth technique. Langmuir 2012. Vol. 20, P. 1-29.

10. Семенов С.А. Планирование эксперимента в химии и химической технологии. Том 1. Учебно-методическое пособие, М.: ИПЦ МИТХТ, 2001. 93 с. [Semenov S.A. Planning of experiments in chemistry and chemical technology. Volume 1. Textbook. Moscow: PPC MITCT, 2001. 93 p. (In Russ.)] 